\title{
A mixed collector system for phosphate flotation
}

\author{
Qinbo Cao ${ }^{\mathrm{a}}$, Jinhua Cheng ${ }^{\mathrm{a}}$, Shuming Wen ${ }^{\mathrm{a} *}$, Chengxiu Li $^{\mathrm{b}}$, Shaojun Bai ${ }^{\mathrm{a}}$, Dan $\mathrm{Liu}^{\mathrm{a}}$
}

${ }^{a}$ State Key Laboratory of Complex Nonferrous Metal Resources Clean Utilization, Faculty of Land Resources Engineering, Kunming University of Science and Technology, Kunming, 650093, Yunnan, PR China

${ }^{\mathrm{b}}$ Institute of Mineral Resource Comprehensive Utilization, Chinese Academy of Geological Sciences, Chengdu 610041, China

* To whom correspondence should be addressed.

Shuming Wen.

Email : shmwen@126.com ; Tel : +86-0871-65153445. 


\section{A mixed collector system for phosphate flotation}

Abstract: Flotation has been used in industry for more than a half century as the primary technique for upgrading phosphate. While the flotation of phosphate was inefficient when oleic acid was used alone as a collector, therefore a mixed collector of oleic acid (HOl), linoleic acid (LA) and linolenic acid (LNA) was employed to improve the recovery of phosphate flotation. The batch flotation results showed that the optimal composition of the mixed collector was $54 \mathrm{wt} . \% \mathrm{HOl}, 36 \mathrm{wt} . \% \mathrm{LA}$ and 10 wt.\% LNA. Additionally, the effect of $\mathrm{pH}$ on the mixed collector application was studied while considering the surface tension, contact angle and micro-flotation. The results showed that the mixed collector should be used at a $\mathrm{pH}$ of 9.5. Above a $\mathrm{pH}$ of 9.5, the adsorption of fatty acids dimers on the apatite surface hindered phosphate flotation. The influence of the mixed collector assembly on apatite flotation was also investigated. It was demonstrated that due to its low critical micelle concentration, a sufficiently hydrophobic apatite surface could be generated at a collector concentration of $60 \mathrm{mg} / \mathrm{L}$. In addition, zeta potential experiments suggested that collector adsorption was governed by chemisorption. FTIR and XPS spectra studies further indicated that the chemical reaction involved the carboxyl groups of fatty acids and $\mathrm{Ca}$ species at the apatite surface for each fatty acid in the mixed collector.

Keywords: phosphate flotation; mixed collector; adsorption state; adsorption mechanism;

\section{Introduction}

Phosphorous is one of the most common elements on Earth and is essential for life in all organisms (Sharpley et al., 1997). Due to its high reactivity, phosphorus is primarily found in its oxidized state (i.e., phosphate) in nature. Phosphates form the backbone of adenosine triphosphate, which stores the chemical energy used in biological systems, and they are also the primary components of the bones and teeth in humans (Arnold and Gaengler, 2007; Helbig et al., 1998a). In its synthetic form, phosphorous is used as a fertilizer and is one of the three primary nutrients for plants.

Phosphate ore is the primary natural resource from which phosphorous is extracted. While apatite is the most prevalent phosphate, other gauge minerals commonly found in phosphate ore are dolomite, calcite and silicates. Increasing global demand for food has increased consumption of phosphate ore to an alarming rate over the past few decades; the year of 2005 boasted a world phosphate production of $148 \mathrm{Mt}$, which was more than twice the production of 1965 (Herring and Fantel, 
1993; Van Vuuren et al., 2010). The USA is the largest phosphate producer and produced approximately one third of the world's 35.8 Mt of phosphate in 2002 (USGS, $2003)$. It was also estimated that over $70 \%$ of the production in the USA occurred at plants in Florida (Pittman, 1990).

To meet the requirement of phosphoric acid production, phosphate ore should be enriched to near $30 \% \mathrm{P}_{2} \mathrm{O}_{5}$ (Abouzeid et al., 2009). Generally, natural phosphate ores fail to meet this market grade and must be upgraded with further processing. For certain high-grade phosphate ores, a satisfactory concentration could be obtained simply using gravity separation methods (Abouzeid, 2008). With the depletion of high-grade phosphate ore, low-grade phosphate ore with more impurities is becoming the primary resource for phosphate; thus, more efficient methods are required for upgrading. Flotation, which uses fatty acids as collectors, is the predominant method for the processing of low-grade ore. Today, it is estimated that more than half of the marketable phosphate in the world undergoes flotation techniques (Sis and Chander, 2003c).

Despite successful and economic recovery of phosphate via flotation, its efficiency using fatty acids as collectors is still not satisfactory. Oleic acid is the most common and traditionally used collector for apatite flotation. One concern in the use of oleic acid is its tendency to adsorb onto a slime surface. A large slime surface area also favours the adsorption of oleic acid (Hernáinz et al., 2004) and thus reduces the flotation selectivity. A significant amount of calcium ions introduced into the pulp by the dissolution of Ca-bearing minerals and from recycle water (Zhang et al., 1999) can react with the oleic acid and precipitate out calcium dioleate salt, leading to high consumption of the collector. Additionally, the use of oleic acid requires high temperatures, resulting in high processing cost (Ge et al., 2008; Sis and Chander, 2003a).

To mitigate the disadvantages of oleic acid mentioned above, many new collectors have been developed. It was reported that a hydroxamic acid-alcohol collector was an efficient and selective collector for phosphate flotation and was suitable for coarse feed (Miller et al., 2002; Wang et al., 2006). Amino acids could also be used for apatite flotation (Hirva and Gordeijev, 1999). The ab initio simulation study revealed that sarcosine anion could bind tridentately or bidentately with $\mathrm{Ca}^{2-}$ (Hirva and Gordeijev, 1999). It was also demonstrated that sarcosine anion could selectively adsorb onto an apatite surface with a bidentate binding but not onto calcite and dolomite surfaces (Hirva and Gordeijev, 1999; Hirva and Tikka, 2002). Though the newly developed collectors showed improved performance for phosphate flotation but have been found limited use in industry due to their high cost and complex processes 
required for synthesis.

Another approach to enhance the performance of oleic acid is using synergic reagents. Synergists could improve the adsorption of oleate ions at the liquid/air interface and to the phosphate surface (Sis and Chander, 2003a, b). In addition, synergists help to prevent the detrimental effects of slime and calcium ions on collector efficiency (Helbig et al., 1998b). Ethoxylated nonylphenol with four oxyethyl groups (NP-4) is a typical non-ionic synergist. It was reported that the critical micelle concentration (CMC) of a 2:1 mixture of oleic acid and NP-4 (50 $\mathrm{mg} / \mathrm{L})$ was significantly below the CMC of pure oleic acid $(500 \mathrm{mg} / \mathrm{L})$ (Sis and Chander, 2003b). The contact angle of apatite also improved $6-7^{\circ}$ using a 2:1 mixture of oleic acid and NP-4.(Sis and Chander, 2003a).

In phosphate plants today, vegetable oils are the dominant collectors that are replacing oleic acid due to their low costs and high efficiencies at normal temperature. Vegetable oils, including corn oil, soybean oil and rice bran oil, have been successfully used as collectors for apatite flotation in Brazil (Guimaraes et al., 2005). These vegetable oils are primarily composed of oleic acid (HOl), linoleic acid (LA) and linolenic acid (LNA), which are not stable even if they are derived from the same vegetable. The content change of each component can affect the flotation property of the vegetable oil; however, the influence of changes in the composition of the vegetable oils on phosphate flotation is still unknown. Guimaraes et al. reported that LA was as effective as HOl, and a high LA fraction in the mixed collector was not necessary for apatite flotation (Guimaraes et al., 2005). Conversely, few reports currently exist in the literature about phosphate flotation with the LNA collector.

Thus, the optimal composition of a mixed fatty acid collector must be determined for phosphate flotation. In addition, the flotation behaviour of this type of mixed collector also must be investigated in detail. Therefore, HOl, LA and LNA were selected as components for a mixed collector in this study. The suitable fraction for each component was first determined directly with the flotation tests using run-of-mine phosphate ore. Fundamental surface chemistry experiments were conducted to reveal the adsorption state of the mixed collector on the apatite surface. The adsorption mechanism for the mixed collector was also determined using FTIR and X-ray photoelectron spectroscopy (XPS).

\section{Experimental}

\subsection{Reagents and Materials}

AR-grade oleic acid (HOl), linoleic acid (LA) and linolenic acid (LNA) were purchased from TCI of Japan. The vegetable oils used were all provided by the 
Institute of Multipurpose Utilization of Mineral Resources, China.

The phosphate ore sample for the batch flotation tests was obtained from the Wenfu Phosphate Company located in Guizhou Province, China. A chemical composition analysis showed that the ore contained $25.50 \% \mathrm{P}_{2} \mathrm{O}_{5}, 18.98 \%$ of acid insoluble (A.I) and $6.83 \%$ of loss on ignition (L.O.I), as shown in Table 1. XRD and MLA analyses indicated phosphate existed in the form of fluorapatite, and primary gauge minerals were hydromica, quartz and dolomite in the ore (Table 2).

The apatite $\left(\mathrm{Ca}_{5}\left(\mathrm{PO}_{4}\right)_{3} \mathrm{~F}\right)$ pebbles with a purity of $98 \%$, which was confirmed by $\mathrm{XRD}$ analysis, were used for the surface property analysis. The apatite pebbles were pre-treated in an ultrasonic cleaner for 5 minutes and dried before the surface tests began. All experiments were conducted at $23^{\circ} \mathrm{C}$. Tap water was used in all batch flotation tests, and deionized water (DI water) was used for the pure apatite study.

\subsection{Batch flotation test}

A 1.5 L flotation cell was prepared for the flotation tests. For each test, $500 \mathrm{~g}$ of phosphate ore was wet ground to $80 \mathrm{wt}$. \% passing 200 mesh with a ball mill. The phosphate pulp was transferred into the flotation cell and stirred for $1 \mathrm{~min} .6 \mathrm{~kg} / \mathrm{t}$ of sodium carbonate was added into the pulp to achieve a $\mathrm{pH}$ of 9.5 with 3 min of conditioning time. Next, $3 \mathrm{~kg} / \mathrm{t}$ of soluble glass was added, and the solution was conditioned for another $3 \mathrm{~min}$. All types of collectors were added with the same dosage of $600 \mathrm{~g} / \mathrm{t}$, and the slurry was stirred for $3 \mathrm{~min}$. Before froth collection, $20 \mathrm{~g} / \mathrm{t}$ of pine oil was added with $1 \mathrm{~min}$ of conditioning time. All conditioning processes were conducted in the absence of airflow. After completion of the flotation test, the float and sink products were filtered, dried, weighed and analysed. In addition, the fatty acids were mixed with different weight fractions and mass ratios to obtain various mixed collectors.

\subsection{Surface tension measurement}

The Du Noüy ring method was used to measure the surface tension of the collector solutions. In the solution preparation, the glassware was cleaned with chromic acid and rinsed with ample DI water. The platinum ring first was flushed with acetone, followed by methanol and DI water. After removing the remaining water, the ring was flame treated to remove any organic contamination. Before each measurement, the surface tension of the DI water was tested as a control. In each test, a $20 \mathrm{~mL}$ sample of solution was used. The $\mathrm{pH}$ was maintained at a desired value with dilute $\mathrm{NaOH}$ and $\mathrm{HCl}$ solutions.

2.4 Contact angle measurement 
The contact angle on the apatite surface was measured with the sessile drop method using a GBX 3S tensiometer. An apatite crystal was dry polished first with 500 grit and then 1000 grit and 4000 grit $\mathrm{Al}_{2} \mathrm{O}_{3}$ sandpapers. The crystal was then air cleaned and plasma treated for 5 minutes to obtain a fresh surface. The crystal was conditioned with the collector solution at the desired concentration and $\mathrm{pH}$ for 15 minutes and then air dried. A DI water droplet $(2 \mathrm{~mm}-3 \mathrm{~mm})$ was then introduced onto the apatite surface. After the three-phase contact line was observed, the syringe was moved upward, and the shape of the free droplet was recorded by a CCD camera system. The image of the droplet was analysed with the software to obtain a contact angle value.

\subsection{Micro-flotation test}

A $125 \mathrm{~mL}$ hallimond tube equipped with a $20-\mu \mathrm{m}$ frit and a magnetic stirrer was used to test the flotation behaviour of the apatite. $3 \mathrm{~g}$ of apatite samples $(-60+80 \mathrm{mesh})$ were used in each experiment. The samples were treated in an ultrasonic bath for 5 min and then transferred into the flotation tube. After $5 \mathrm{~min}$ of conditioning, the samples were floated for $1 \mathrm{~min}$ with nitrogen at a flow rate of $30 \mathrm{~mL} / \mathrm{min}$. The froth product was collected and dried to calculate the recovery.

\subsection{TOC content measurement}

$1 \mathrm{~g}$ of apatite powder $(-45 \mu \mathrm{m})$ was introduced into $100 \mathrm{~mL}$ of collector solution at the desire concentration and at a $\mathrm{pH}$ of 9.5. After stirring for $30 \mathrm{~min}$, the suspension was filtered, and the clear liquor was taken for TOC analysis. The TOC amounts of the original collector solutions were also tested to obtain the TOC reduction due to apatite adsorption.

\subsection{Zeta potential analysis}

A zeta potential analysis was conducted with a Zetasizer Helix instrument from Malvern. $0.1 \mathrm{~g}$ of $-45 \mu \mathrm{m}$ apatite was first conditioned with $100 \mathrm{~mL}$ of solution for 20 min while being stirred at $250 \mathrm{rpm}$. After conditioning for another $20 \mathrm{~min}$ without stirring, $10 \mathrm{~mL}$ of the supernatant liquid was transferred into the measurement cell to measure its zeta potential.

\subsection{FTIR spectrum}

The FTIR spectra of the apatite before and after collector adsorption were recorded in the range from 400 to $4000 \mathrm{~cm}^{-1}$ with an Avatar 300 from the Thermo Electron Co. $0.15 \mathrm{~g}$ of apatite $(-45 \mu \mathrm{m})$ was equilibrated with $100 \mathrm{~mL}$ of the collector solution at a concentration of $100 \mathrm{mg} / \mathrm{L}$ and at a $\mathrm{pH}$ of 9.5 ; the solution was stirred at $250 \mathrm{rpm}$ for $24 \mathrm{~h}$. After conditioning, the apatite sample was gently washed three 
times with DI water and air-dried. $50 \mathrm{mg}$ of apatite was then mixed with $100 \mathrm{mg}$ of $\mathrm{KBr}$ powder in an agate. The mixture was ground to further reduce the particle size and complete mixing. The powdered mixture was then pressed into a thin plate for FTIR analysis.

\subsection{XPS spectra study}

X-ray Photoelectron Spectroscopy (XPS) experiments were conducted with a PHI 5000 Versa Probe II equipped with an Al target. Apatite samples $(-45 \mu \mathrm{m})$ were treated with the collector solutions at conditions identical to those in the FTIR spectra study. Then, $0.15 \mathrm{~g}$ of apatite powder was directly pressed into a plate without the addition of $\mathrm{KBr}$ powder. The spectra were analysed with MultiPak Spectrum software. All spectra were adjusted based on the standard $\mathrm{C}_{1 \mathrm{~s}}$ binding energy $(286.4 \mathrm{eV})$ and were further fitted using the Gauss-Lorentz method with $3.60 \mathrm{eV}$ of separation for the $\mathrm{Ca}_{2 \mathrm{p} 3 / 2}$ and $\mathrm{Ca}_{2 \mathrm{p} 1 / 2}$ peaks.

\section{Results and Discussion}

3.1 Determination of the fatty acid composition in the mixture

In this section, the flotation capacities of the HOl, LA and their mixtures were first evaluated with batch flotation tests; the results are shown in Fig. 1.

After a single stage of flotation, the effect of changing the collector blend showed little effect on concentrate grade, which was shown to be $25 \%$. However, the phosphate recovery was higher when the fraction of LA was increased. When using pure LA, $\mathrm{P}_{2} \mathrm{O}_{5}$ recovery was approximately $85 \%$. In comparison, $\mathrm{P}_{2} \mathrm{O}_{5}$ recovery was $68 \%$ when pure $\mathrm{HOl}$ was used. This shows that LA was a more effective collector than $\mathrm{HOl}$ for phosphate flotation. However, due to the high cost of LA, LA is rarely used as an apatite collector. In addition, $\mathrm{P}_{2} \mathrm{O}_{5}$ recovery increased by approximately $13 \%$ as the fraction of LA increased from 0 to $40 \mathrm{wt} . \%$. Above $40 \mathrm{wt} . \%$, an increase in LA content did not affect the $\mathrm{P}_{2} \mathrm{O}_{5}$ recovery, indicating that a high LA fraction was not necessary for apatite flotation. Therefore, the appropriate ratio of $\mathrm{HOl}$ to LA in their mixture was determined to be 3:2 for phosphate flotation.

The suitable fraction of LNA in the mixed collector was also investigated. Due to the low content of LNA in most vegetable oils, the fraction limit of LNA in the mixed collector was established to be $30 \mathrm{wt} . \%$ in the flotation tests. Additionally, the ratio of $\mathrm{HOl}$ to LA was kept at 3:2 in the surfactant mixtures despite the change in content of the LNA. Based on the results in Fig. 2, the highest $\mathrm{P}_{2} \mathrm{O}_{5}$ recovery (88.44\%) was achieved with 10 wt.\% of LNA. A further increase in the LNA fraction did not improve phosphate flotation. With $30 \mathrm{wt} \%$ of LNA, the $\mathrm{P}_{2} \mathrm{O}_{5}$ recovery was only 
83.3\%. These results suggested that the $10 \mathrm{wt} . \%$ LNA in the mixed collector was ideal.

In this regard, the optimal composition of the mixed collector for phosphate flotation was determined by two series of flotation tests to be 54 wt.\% HOl, 36 wt.\% LA and $10 \mathrm{wt} . \%$ LNA. In the flowing experiments, the mixed collector was used in its optimal composition.

\subsection{Comparison of the mixed collector and vegetable oils}

The flotation capacities of the vegetable oils and the mixed collector were all evaluated, as shown in Fig. 3. The grades of concentrates were near $27 \%$ for all of the collectors studied; however, the recovery was highly dependent on the type of collector used. The highest recovery $(90.26 \%)$ was achieved with the mixed collector.

As expected, the distinctions in flotation recovery resulted from the content differences of these collectors (Table 3). The corn oil and the mixed collector exhibited similar flotation abilities due to their similar compositions. In the case of the bean oil, LA was the major component (57.32 wt.\%). As shown above, LA was more efficient than $\mathrm{HOl}$, and a high content of LA would not deteriorate the phosphate flotation. Thus, the decreased recovery with the bean oil was attributed to the low content of LNA in the bean oil. In the case of the castor oil, the decreased recovery was primarily caused by its low contents of $\mathrm{HOl}$ and LA.

The lowest recovery was observed using the rice oil. In the rice oil, hexadecanoic acid was a major component, while the contents of $\mathrm{HOl}$ and LNA were low. Therefore, the flotation results indicated that hexadecanoic acid was not as efficient as $\mathrm{HOl}$ or LNA for phosphate flotation.

The flotation results demonstrated that the mixed collector exhibited a superior capacity for phosphate flotation, and a vegetable oil with a similar composition to that of the mixed collector could act as a reasonable phosphate collector.

\subsection{Effect of $\mathrm{pH}$ on the mixed collector adsorption}

Surface tension and contact angle experiments were conducted to analyse the influence of $\mathrm{pH}$ on the reagent adsorption at the air/liquid interface as well as the solid/liquid interface.

It was shown in Fig. 4 that increasing $\mathrm{pH}$ improved collector adsorption at the air/liquid interface, which produced a sharp reduction in the surface tension at any $\mathrm{pH}$; conversely, changes in the contact angle were observed over two distinct $\mathrm{pH}$ ranges. Between a $\mathrm{pH}$ of 3 and 9 , the contact angle increased by approximately 20 degrees for 
both concentrations; at a $\mathrm{pH}$ of 11.5 , the apatite surface became less hydrophobic, as indicated by a decreasing contact angle.

The contact angle results should be considered with respect to the species distribution of the fatty acids in solution. However, only the thermodynamic data of $\mathrm{HOl}$ was reported in detail (A.Martinez L and A.Uribe S, 1995). Because the fatty acids in the mixed collector have identical head groups and similar hydrocarbon chains, only differing in the number of $\mathrm{C}=\mathrm{C}$ bonds, it was expected that these fatty acids had similar species distribution in aqueous solutions.

Similarly, HOl, LA and LNA molecules were the dominant species in the acidic solution, which allows these fatty acids molecules to physically adsorb onto the apatite surface (Lu et al., 1998). This weak adsorption resulted in a low contact angle (Fig. 4). In weak alkaline solutions, ions and ion-molecule complexes of fatty acids both presented in the collector solutions. These species could adsorb at the apatite surface, which significantly improved the hydrophobicity of the apatite (Free and Miller, 1996; Lu et al., 1998; Nunes et al., 2011). However, at a pH above 10, the fatty acids dimers became the major species in which two fatty acids ions arranged in reverse (Vučinić et al., 2010). Therefore, when a fatty acid dimer adsorbed to the apatite surface, the head group of one molecule in the dimer must be facing the solution, resulting in a decrease in the contact angle.

The contact angle results were further supported by the micro-flotation tests. In a basic solution, the $\mathrm{P}_{2} \mathrm{O}_{5}$ recovery was limited for all concentrations (Fig. 5). The highest recovery was obtained at a $\mathrm{pH}$ of 9.5 , followed by a decrease at a $\mathrm{pH}$ of 11.5 at $20 \mathrm{mg} / \mathrm{L}$ or $40 \mathrm{mg} / \mathrm{L}$. Thus, a $\mathrm{pH}$ of 9.5 was considered to be suitable for the application of the mixed collector.

\subsection{Mixed collector characterization}

At a $\mathrm{pH}$ of 9.5, the assembly and adsorption states of the mixed collector at the mineral surface were further detailed, which provided important information about the interface controlling during the phosphate flotation.

As indicated in Fig. 6, the premicellar concentration and the critical micelle concentration (CMC) of $\mathrm{HOl}$ were $15 \mathrm{mg} / \mathrm{L}$ and $300 \mathrm{mg} / \mathrm{L}$, respectively. In the case of the mixed collector, the premicellar concentration was $30 \mathrm{mg} / \mathrm{L}$, and the $\mathrm{CMC}$ was only $70 \mathrm{mg} / \mathrm{L}$, which was significantly lower than of the HOl. The results indicated that in mixed collector solutions, fatty acids ions could be in the form of hemmicelles at concentrations between $30 \mathrm{mg} / \mathrm{L}$ and $70 \mathrm{mg} / \mathrm{L}$ and began to associate as micelles above $70 \mathrm{mg} / \mathrm{L}$. 
The influence of the assembly state of the collectors on apatite flotation was further investigated with the contact angle results (Fig. 7). In the mixed collector solutions, the contact angle was limited to within 55 degrees below $20 \mathrm{mg} / \mathrm{L}$. In the range from $30 \mathrm{mg} / \mathrm{L}$ to $80 \mathrm{mg} / \mathrm{L}$, the fatty acid hemimicelles adsorbed onto the apatite surface in a tightly packed manner. Therefore, a significant increase in the contact angle was found in this concentration range. Above $80 \mathrm{mg} / \mathrm{L}$, the fatty acids ions arranged in a bilayer structure on the apatite surface due to the presence of fatty acids micelles, which could lead to a decrease in the contact angle (Bremmell et al., 1999; Wang et al., 2006). In addition, the $\mathrm{HOl}$ also behaved in a similar fashion to the mixed collector.

The above analysis of the contact angle results was further supported by the TOC experiments with the mixed collector. The significant decrease in the TOC content at a concentration of $90 \mathrm{mg} / \mathrm{L}$, as shown in Fig. 8, indicated that more collectors adsorbed onto the apatite surface. Thus, it was proved that a reduction of the contact angle at 90 $\mathrm{mg} / \mathrm{L}$ resulted from the adsorption of micelles rather than the reduction of collectors at the apatite surface.

\subsection{Zeta potential measurement}

As shown in Fig. 9, when the apatite samples were in solution without a collector, the point of zero charge (PZC) of the apatite was visible near a $\mathrm{pH}$ of 4.5, which agreed with a previous study $(\mathrm{Hu}$ and $\mathrm{Xu}, 2003)$. As suggested by Vučinić et al. (Vučinić et al., 2010), the increase in the negative zeta potential from a pH of 4.5 to 9 was caused by the adsorption of $\mathrm{OH}^{-}$and/or $\mathrm{HPO}_{4}{ }^{2-}$ at the apatite surface in the DI water; the further decrease of the zeta potential was thus achieved by adsorption with $\mathrm{CO}_{3}{ }^{2-}$ and/or $\mathrm{HCO}_{3}{ }^{-}$at a $\mathrm{pH}>9$.

In terms of the apatite samples in the collector solutions, all of the zeta potentials shifted towards more negative values than the results in the DI water. The fatty acid ions could not physically adsorb onto the negative apatite surface due to electrostatic repulsion. It was expected that chemisorption was achieved by the fatty acids ions on the apatite surface.

The zeta potential variations below $90 \mathrm{mg} / \mathrm{L}$ could be explained based on the species distribution of the mixed collector. As discussed above, at a $\mathrm{pH}$ from 5 to 7 , fatty acid molecules were the prevalent species and thus did not contribute to the change in zeta potential. The decrease in the zeta potential in this $\mathrm{pH}$ range was caused by the adsorption fatty acid ions in small amounts. In a weak alkaline solution $(7<\mathrm{pH}<9.5)$, the ions and ion-molecule complexes of the fatty acids were present in the solution; the adsorption of these species produced a rise in the negative zeta 
potential.

At a $\mathrm{pH}$ of 11.5 , the fatty acid dimers adsorbed onto the apatite surface, which further decreased the zeta potential; the fatty acid micelles could occur in the solutions and adsorb onto the apatite surface at $90 \mathrm{mg} / \mathrm{L}$, which introduced a significant decrease in the zeta potential compared with those at $20 \mathrm{mg} / \mathrm{L}$ and $30 \mathrm{mg} / \mathrm{L}$.

\subsection{FTIR spectra analysis}

The assembly and adsorption states of the mixed collector at the apatite surface were described in detail by the above measurements of the surface properties. Here we investigated the adsorption mechanism for the mixed collector system by using FTIR techniques.

The corresponding peaks of P-O are presented in Fig. 10. The peaks at $600 \mathrm{~cm}^{-1}$ and $575 \mathrm{~cm}^{-1}$ are due to P-O bending. P-O asymmetrical stretching are shown at 1042 $\mathrm{cm}^{-1}$ and $1093 \mathrm{~cm}^{-1}$ (Peng Wenshi et al., 1986). The peaks for P-O band before and after collector adsorption are shown without any significant shift, which indicates that no reaction occurred between the fatty acid ions and the surface $\mathrm{P}$ species on the apatite surface.

Conversely, Fig. 11 summarizes the spectra of natural apatite and apatite after treatment with the mixed collector from $1480 \mathrm{~cm}^{-1}$ to $3200 \mathrm{~cm}^{-1}$. The spectrum of apatite in this range was nearly linear without any peaks. The finite peak at $2850 \mathrm{~cm}^{-1}$, which corresponds to $\mathrm{CH}_{2}$ stretching, was observed, indicating the complete adsorption of the collector. Additionally, a strong peak at $1710 \mathrm{~cm}^{-1}$ was also detected due to $\mathrm{C}=\mathrm{O}$ stretching in the carboxyl group in the mixed collector. However, this peak disappeared at the apatite surface after collector adsorption, and two new peaks at $1652 \mathrm{~cm}^{-1}$ and $1606 \mathrm{~cm}^{-1}$ were observed.

The disappearance of the peak at $1710 \mathrm{~cm}^{-1}$ indicated that the reaction involved a carboxyl group in the fatty acid molecules. It has been shown that the $\mathrm{HOl}$ adsorption was controlled by the surface precipitation of calcium dioleate, which was indicated by a doublet peak at $1570 \mathrm{~cm}^{-1}$ and $1540 \mathrm{~cm}^{-1}$ (Lu et al., 1998). Thus, it was rational to expect that the new peaks at $1652 \mathrm{~cm}^{-1}$ and $1606 \mathrm{~cm}^{-1}$ were formed by contributions from the alkyl carboxylates of LA, LNA and HOl.

\subsection{XPS study}

The XPS technique can determine the chemical states of elements, which is valuable to analyse the adsorption phenomena on a mineral surface during flotation ( $\mathrm{Ji}$ et al., 2005; Ren et al., 2004). To confirm the FTIR results above, the XPS technique was used to measure the binding energies of $\mathrm{Ca}_{2 p}$ in the apatite samples before and 
after collector adsorption.

The fitted results of the $\mathrm{Ca}_{2 p}$ spectra are shown in Fig. 12. The binding energies of $\mathrm{Ca}_{2 \mathrm{p} 3 / 2}$ and $\mathrm{Ca}_{2 \mathrm{p} 1 / 2}$ were $347.21 \mathrm{eV}$ and $350.81 \mathrm{eV}$, respectively, in the natural apatite. After treating the apatite with each fatty acid, the binding energy of $\mathrm{Ca}_{2 \mathrm{p} 3 / 2}$ changed by $0.48 \mathrm{eV}$ for $\mathrm{HOl}, 0.28 \mathrm{eV}$ for LA and $0.17 \mathrm{eV}$ for LNA. In addition, in the mixed collector system, a $0.40 \mathrm{eV}$ change in the binding energy could be attributed to the contributions of the fatty acids in the mixed collector. On the other hand, due to the same separation value for the $\mathrm{Ca}_{2 \mathrm{p} 3 / 2}$ and the $\mathrm{Ca}_{2 \mathrm{p} 1 / 2}$ peaks, the changes in the binding energy for the two peaks were identical for the same sample.

The changes in the binding energy of $\mathrm{Ca}_{2 \mathrm{p}}$ demonstrated that chemical adsorption did occur at the $\mathrm{Ca}$ sites on the apatite surface. Therefore, it was concluded that the adsorption of the mixed collector depended on the reaction between the carboxyl groups and the Ca species on the apatite surface.

4 Conclusions

The primary conclusions of this study are listed as follows:

(1) The ideal composition of a mixed collector was determined by batch flotation tests to be 54 wt.\% HOl, 36 wt.\% LA and $10 \mathrm{wt} . \%$ LNA for phosphate flotation. With respect to natural vegetable oils, an equivalent recovery could be achieved only when the composition of the vegetable oil was similar to that of the ideal mixed collector.

(2) A reasonable $\mathrm{pH}$ for the application of the mixed collector was determined to be a $\mathrm{pH}$ of 9.5 by the contact angle and micro-flotation experiments. Above a $\mathrm{pH}$ of 9.5, the fatty acid dimers could adsorb onto the apatite surface, decreasing the hydrophobicity of the apatite surface.

(3) The $\mathrm{CMC}$ for the mixed collector was $70 \mathrm{mg} / \mathrm{L}$ at a $\mathrm{pH}$ of 9.5 , which was significantly lower than the $300 \mathrm{mg} / \mathrm{L}$ of $\mathrm{HOl}$. The highest contact angle was achieved at $60 \mathrm{mg} / \mathrm{L}$ due to the tighter packing of the hemimicelles on the apatite surface. At a concentration exceeding the $\mathrm{CMC}$, a bilayer structure of the collector ions was established, resulting in a decrease in the contact angle.

(4) The zeta potential experiments implied that chemical adsorption was achieved on the apatite surface. The FTIR analysis showed that the carboxyl groups of the fatty acids participated in the chemical reaction. The XPS analysis further corroborated the results of the zeta potential and FTIR spectra tests. For each fatty acid in the mixed collector, the reaction involved the carboxyl groups of tatty acids and the Ca species on the apatite surface, as shown by the changes in the binding energy for $\mathrm{Ca}_{2 p}$. 


\section{ACKNOWLEDGEMENTS}

The financial support provided by the Yunnan Province program KKSY201221120, the Ph.D. Programs Foundation of Ministry of Education of China 20135314120007 and NSF grant No. 51304089 is gratefully acknowledged.

\section{Reference:}

A.Martinez L, A.Uribe S, Intefacial Properties of Celestite and Strontianite in Aqueous Solutions. Minerals Engineering, 1995, 8(9), 1009-1022.

Abouzeid, A.Z.A., Physical and thermal treatment of phosphate ores - An overview. International Journal of Mineral Processing, 2008, 85(4), 59-84.

Abouzeid, A.Z.M., Negm, A.T., Elgillani, D.A., Upgrading of calcareous phosphate ores by flotation: Effect of ore characteristics. International Journal of Mineral Processing, 2009, 90(1-4), 81-89.

Arnold, W.H., Gaengler, P., Quantitative analysis of the calcium and phosphorus content of developing and permanent human teeth. Annals of Anatomy Anatomischer Anzeiger, 2007, 189(2), 183-190.

Bremmell, K.E., Jameson, G.J., Biggs, S., Adsorption of ionic surfactants in particulate systems: flotation, stability, and interaction forces. Colloids and Surfaces A: Physicochemical and Engineering Aspects, 1999, 146(1-3), 75-87.

Free, M.L., Miller, J.D., The significance of collector colloid adsorption phenomena in the fluorite/oleate flotation system as revealed by FTIR/IRS and solution chemistry analysis. International Journal of Mineral Processing, 1996, 48(3-4), 197-216.

Ge, Y.Y., Gan, S.P., Zeng, X.B., Yu, Y.F., Double reverse flotation process of collophanite and regulating froth action. T Nonferr Metal Soc, 2008, 18(2), 449-453.

Guimaraes, R.C., Araujo, A.C., Peres, A.E.C., Reagents in igneous phosphate ores flotation. Minerals Engineering, 2005, 18(2), 199-204.

Helbig, C., Baldauf, H., Mahnke, J., Stöckelhuber, K., Schulze, H., Investigation of Langmuir monofilms and flotation experiments with anionic/cationic collector mixtures. International Journal of Mineral Processing, 1998a, 53(3), 135-144.

Helbig, C., Baldauf, H., Mahnke, J., Stöckelhuber, K.W., Schulze, H.J., Investigation of Langmuir monofilms and flotation experiments with anionic/cationic collector mixtures. International Journal of Mineral Processing, 1998b, 53(3), 135-144.

Hernáinz, F., Calero, M., Blázquez, G., Flotation of low-grade phosphate ore. Advanced Powder Technology, 2004, 15(4), 421-433.

Herring, J.R., Fantel, R.J., Phosphate rock demand into the next century: Impact on wolld food supply. Nonrenewable Resources, 1993, 2(3), 226-246.

Hirva, P., Gordeijev, J., Theoretical studies on the interaction of oleoyl sarcosine with the surface of apatite. Surface Science, 1999, 440(3), 321-326.

Hirva, P., Tikka, H.K., Ab initio study on the interaction of anionic collectors with calcite and dolomite surfaces. Langmuir, 2002, 18(12), 5002-5006.

$\mathrm{Hu}, \mathrm{Y} ., \mathrm{Xu}, \mathrm{Z}$., Interactions of amphoteric amino phosphoric acids with 
calcium-containing minerals and selective flotation. International Journal of Mineral Processing, 2003, 72(1-4), 87-94.

Ji, F.F., Ren, H., Qiao, J.K., Tao, D., Chen, G.L., An investigation of niobite flotation with octyl diphosphonic acid as collector. International Journal of Mineral Processing, 2005, 76(1), 111-122.

Lu, Y., Drelich, J., Miller, J.D., Oleate Adsorption at an Apatite Surface Studied by Ex-Situ FTIR Internal Reflection Spectroscopy* 1. Journal of Colloid and Interface Science, 1998, 202(2), 462-476.

Miller, J., Wang, X., Li, M., 2002. Bench scale flotation of sedimentary phosphate rock with hydroxamic acid collectors, In Proceedings of the Engineering Foundation Conference on Beneficiation of Phosphate III, St. Pete Beach, Florida, eds. Zhang, P., El-Shall, H., Wiegel, R., Littleton, Colorado, pp. 93-101.

Nunes, A.P.L., Peres, A.E.C., de Araujo, A.C., Valadão, G.E.S., Electrokinetic properties of wavellite and its floatability with cationic and anionic collectors. Journal of Colloid and Interface Science, 2011, 361(2), 632-638.

Peng Wenshi, Liu Gaokui, Ke Liqin, Infrared absorption spectra of some apatite minerals. Acta Mineralogica Sinica, 1986(1-4), 26-36.

Pittman, W.E., The Florida phosphate industry. Fertilizer research, 1990, 25(3), 193-196.

Ren, H., Ji, F.F., Chen, G.L., Tao, D., Qiao, J.K., Ren, H., Ji, F.F., Chen, G.L., Qiao, J.K., An investigation of fersmite flotation. International Journal of Mineral Processing, 2004, 74(1), 271-279.

Sharpley, A., Rekolainen, S., Tunney, H., Carton, O., Brookes, P., Johnston, A., 1997. Phosphorus in agriculture and its environmental implications, In Phosphorus loss from soil to water. Proceedings of a workshop, Wexford, Irish Republic, 29-31 September 1995. CAB INTERNATIONAL, pp. 1-53.

Sis, H., Chander, S., Adsorption and contact angle of single and binary mixtures of surfactants on apatite. Minerals Engineering, 2003a, 16(9), 839-848.

Sis, H., Chander, S., Improving froth characteristics and flotation recovery of phosphate ores with nonionic surfactants. Minerals Engineering, 2003b, 16(7), 587-595.

Sis, H., Chander, S., Reagents used in the flotation of phosphate ores: a critical review. Minerals Engineering, 2003c, 16(7), 577-585.

USGS, 2003. "Mineral Commodity Summaries, Phosphate Rock", ed. Survey, U.S.G. Van Vuuren, D.P., Bouwman, A., Beusen, A., Phosphorus demand for the 1970-2100 period: a scenario analysis of resource depletion. Global environmental change, 2010, 20(3), 428-439.

Vučinić, D.R., Radulović, D.S., Deušić, S.Đ., Electrokinetic properties of hydroxyapatite under flotation conditions. Journal of Colloid and Interface Science, 2010, 343(1), 239-245.

Wang, X., Nguyen, A.V., Miller, J.D., Selective attachment and spreading of hydroxamic acid-alcohol collector mixtures in phosphate flotation. International Journal of Mineral Processing, 2006, 78(2), 122-130.

Zhang, P., Yu, Y., Hanson, H., Snow, R., Fundamentals and practical implications of 
the role of polymers in separating silica from phosphate. Beneficiation of Phosphates: Advances in Research and Practice, 1999, 41-52.

\section{Captions:}

Table 1 Chemical composition analysis of the phosphate ore

Table 2 Minerals composition of the phosphate ore

Table 3 Contents of the vegetable oils

Fig. 1 Flotation results with mixtures of $\mathrm{HOl}$ and LA at different combinations

Fig. 2 Flotation results for fatty acids mixtures containing LNA at different fractions (HOl: LA ratio is 3:2)

Fig. 3 Flotation results with the mixed collector and selected vegetable oils

Fig. 4 Effect of $\mathrm{pH}$ on the surface tension and contact angle at $20 \mathrm{mg} / \mathrm{L}$ and $40 \mathrm{mg} / \mathrm{L}$ of the mixed collector (a, surface tension; $b$, contact angle)

Fig. 5 Influence of $\mathrm{pH}$ on the apatite recovery with the mixed collector

Fig. 6 Surface tension variation as a function of the concentrations of $\mathrm{HOl}$ and the mixed collector at a $\mathrm{pH}$ of 9.5

Fig. 7 Dependency of the contact angle on the concentrations of $\mathrm{HOl}$ and the mixed collector

Fig. 8 TOC content of the mixed collector solution before and after apatite adsorption. (The reduction of TOC content is noted above the column.)

Fig. 9 Effect of the concentration of the mixed collector and the $\mathrm{pH}$ on the zeta potential of the apatite

Fig. 10 FTIR spectra of the apatite before (1) and after (2) the mixed collector adsorption in the range from $400 \mathrm{~cm}^{-1}$ to $1300 \mathrm{~cm}^{-1}$

Fig. 11 FTIR spectra of the mixed collector (1), the apatite before (2) and after (3) reaction with the mixed collector in the range from $1480 \mathrm{~cm}^{-1}$ to $3200 \mathrm{~cm}^{-1}$

Fig. $12 \mathrm{Ca}_{2 \mathrm{p}}$ XPS spectra of the natural apatite (A) and the apatite conditioned with $\mathrm{HOl}(\mathrm{B}), \mathrm{LA}(\mathrm{C}), \mathrm{LNA}(\mathrm{D})$, the mixed collector (E) 
Table 1 Chemical composition analysis of the phosphate ore

\begin{tabular}{ccccccccccc}
\hline $\begin{array}{c}\text { Element } \\
\text { composition }\end{array}$ & $\mathrm{P}_{2} \mathrm{O}_{5}$ & $\mathrm{CaO}$ & $\mathrm{MgO}$ & $\mathrm{SiO}_{2}$ & $\mathrm{Fe}_{2} \mathrm{O}_{3}$ & $\mathrm{Al}_{2} \mathrm{O}_{3}$ & $\mathrm{SO} 3$ & $\mathrm{~K}_{2} \mathrm{O}$ & A.I & L.O.I \\
\hline Wt.\% & 25.50 & 37.22 & 1.77 & 19.31 & 1.83 & 4.38 & 2.85 & 1.66 & 18.98 & \\
\hline
\end{tabular}

Table 2 Minerals compositions of the phosphate ore

\begin{tabular}{ccccc}
\hline Minerals & Fluorapatite & Carbonate & Silicoide & Other \\
\hline Wt.\% & 65.11 & 7.98 & 23.35 & 3.56 \\
\hline
\end{tabular}

Table 3 Contents of vegetable oils

\begin{tabular}{cccccc}
\hline \multirow{2}{*}{ Collector } & \multicolumn{5}{c}{ Content of components , wt. \% } \\
\cline { 2 - 6 } & Hexadecanoic acid & Stearic acid & HOl & LA & LNA \\
\hline Mixed collector & - & - & 54 & 36 & 10 \\
Corn oil & 8.07 & 2.48 & 44.73 & 28.55 & 15.81 \\
Bean oil & 8.45 & 3.55 & 27.92 & 57.32 & 2.61 \\
Castor oil & 8.39 & 1.45 & 48.21 & 29.19 & 2.69 \\
Rice oil & 26.13 & 1.93 & 39.87 & 30.69 & 0.86 \\
\hline
\end{tabular}




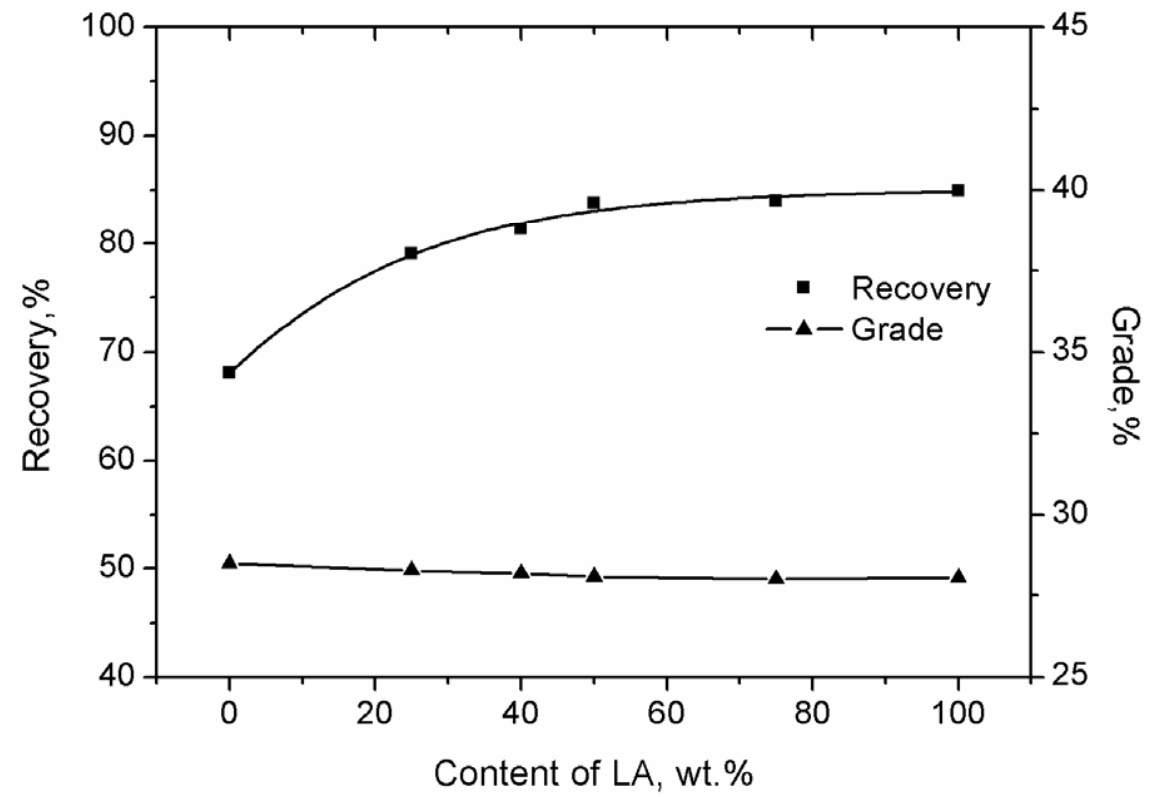

Fig. 1. Flotation results with mixtures of $\mathrm{HOl}$ and $\mathrm{LA}$ at different combinations 


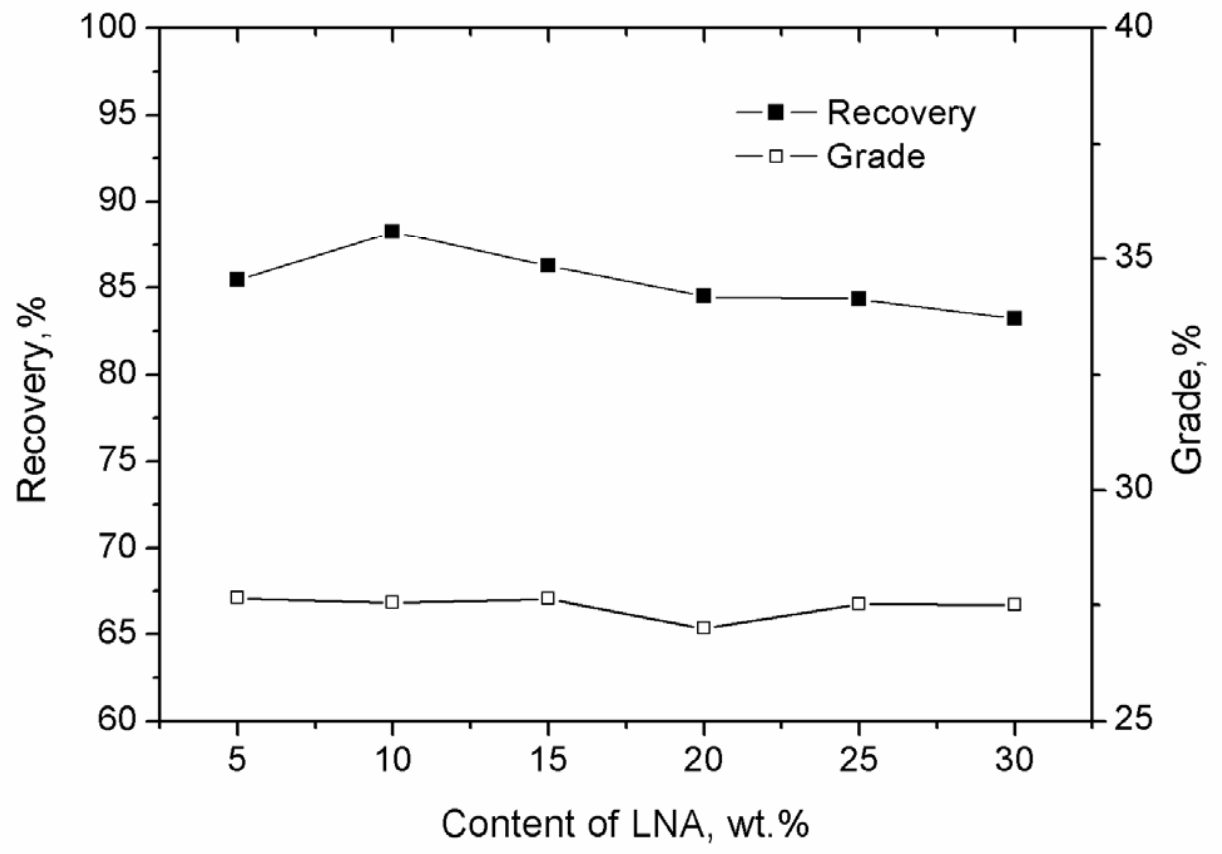

Fig. 2. Flotation results for fatty acids mixtures containing LNA at different fractions (HOl: LA ratio is $3: 2$ ) 


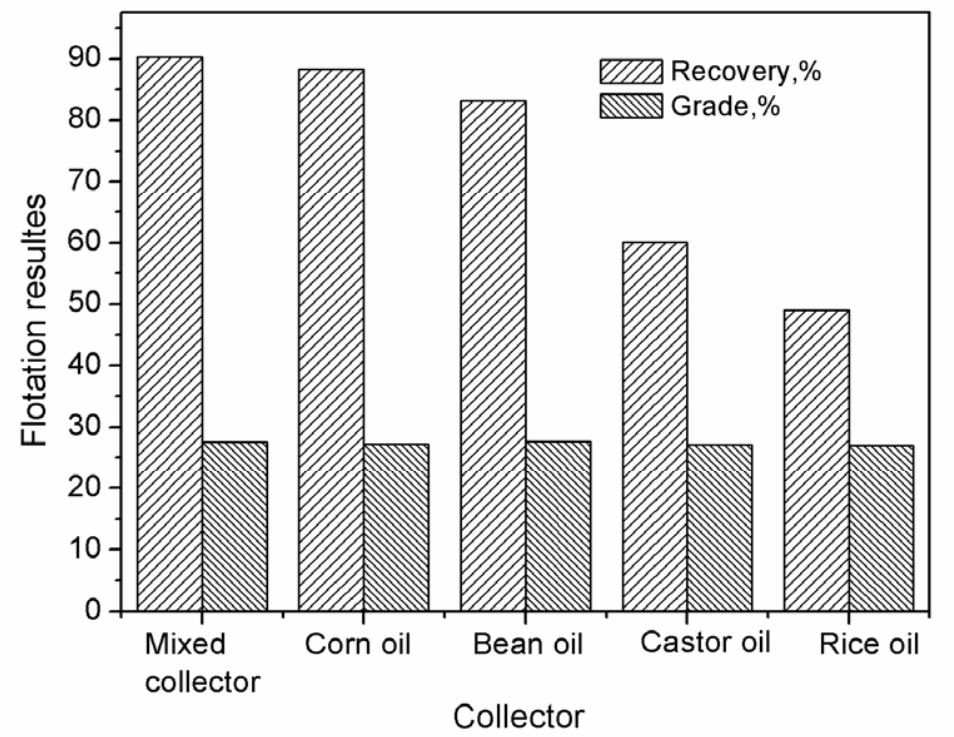

Fig. 3. Flotation results with the mixed collector and selected vegetable oils 


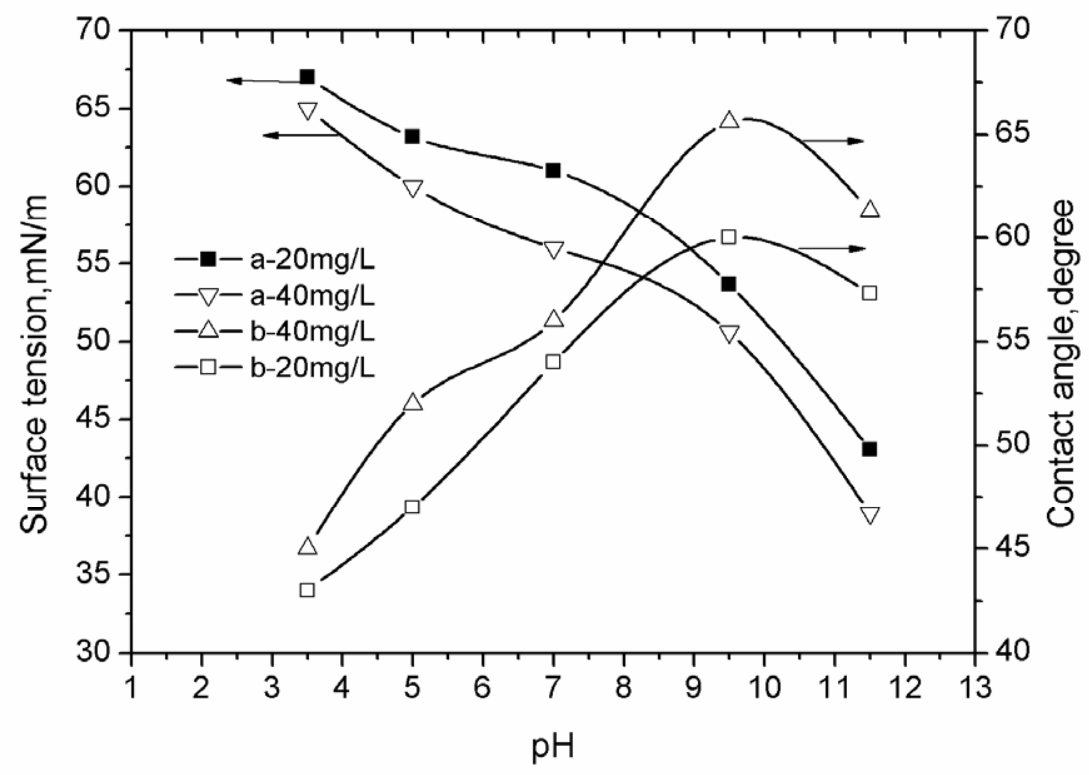

Fig. 4. Effect of $\mathrm{pH}$ on the surface tension and contact angle at $20 \mathrm{mg} / \mathrm{L}$ and $40 \mathrm{mg} / \mathrm{L}$ of the mixed collector ( $a$, surface tension; $b$, contact angle) 


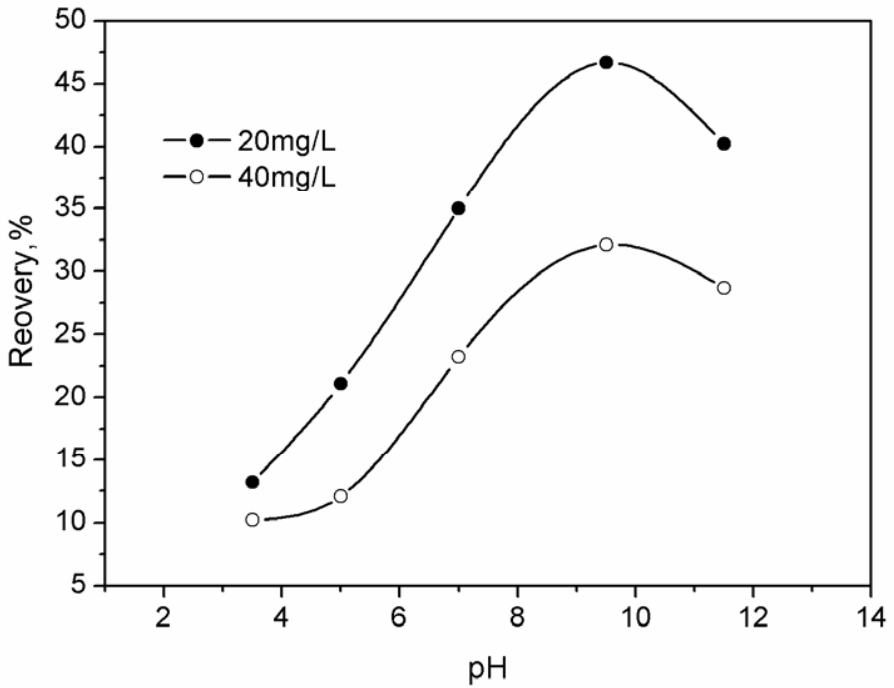

Fig. 5. Influence of $\mathrm{pH}$ on the apatite recovery with the mixed collector 


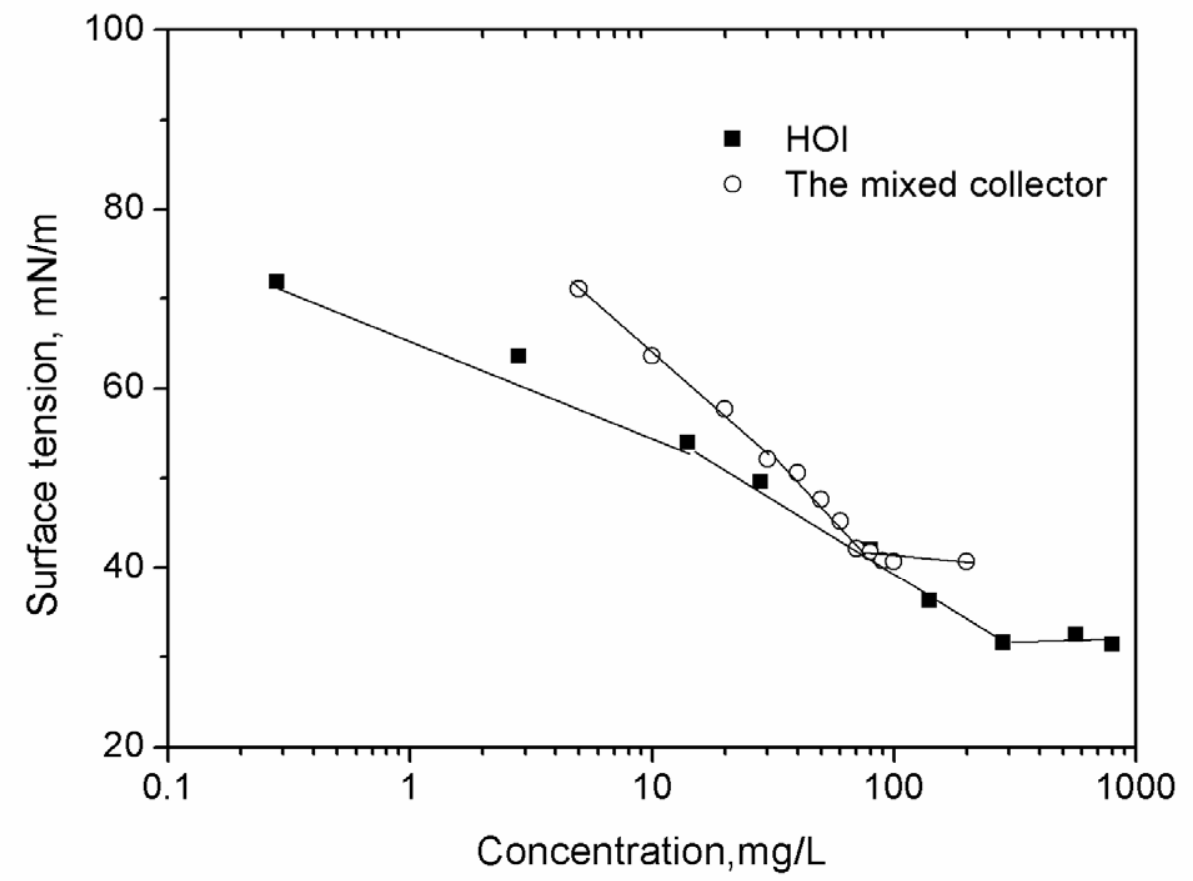

Fig. 6. Surface tension variation as a function of the concentrations of $\mathrm{HOl}$ and the mixed collector at a $\mathrm{pH}$ of 9.5 


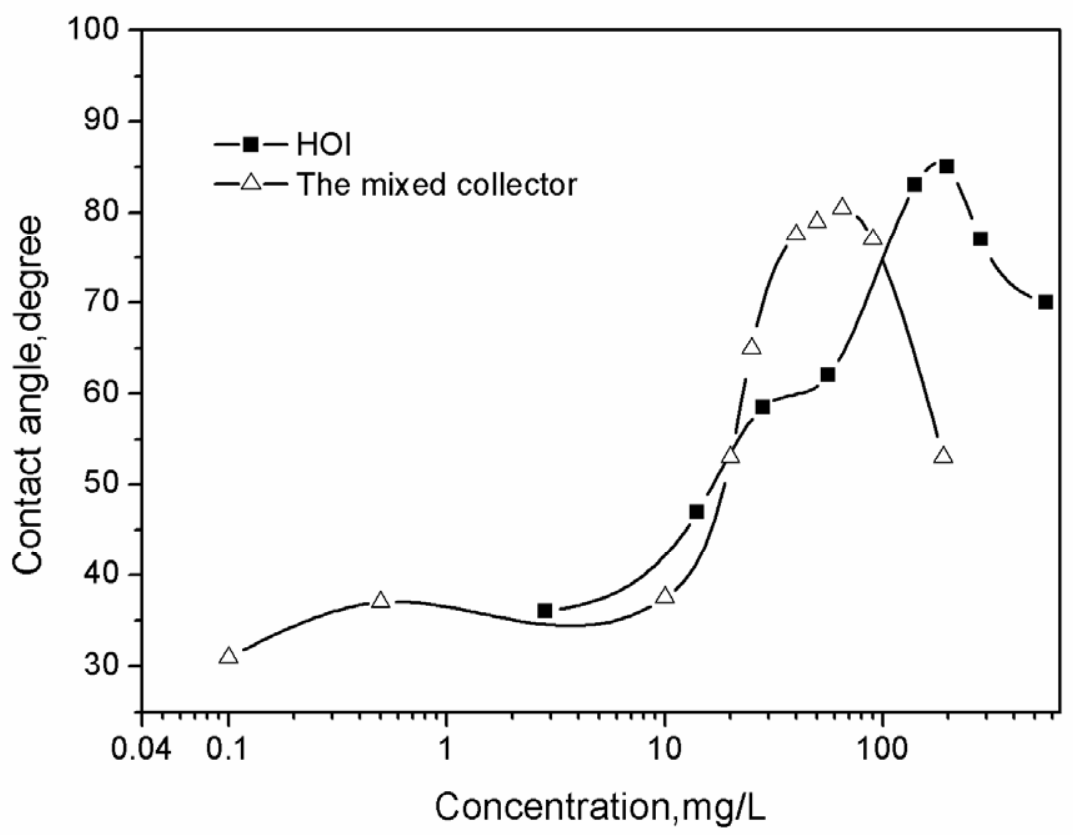

Fig. 7. Dependency of the contact angle on the concentrations of $\mathrm{HOl}$ and the mixed collector 


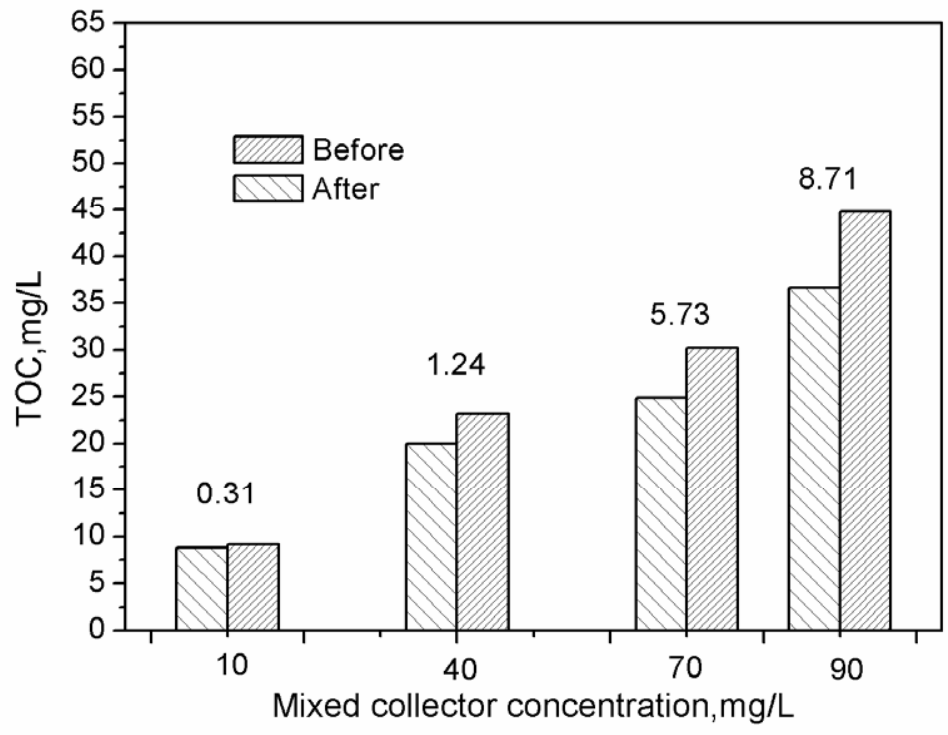

Fig. 8. TOC content of the mixed collector solution before and after apatite adsorption.(The reduction of TOC content is noted above the column.) 


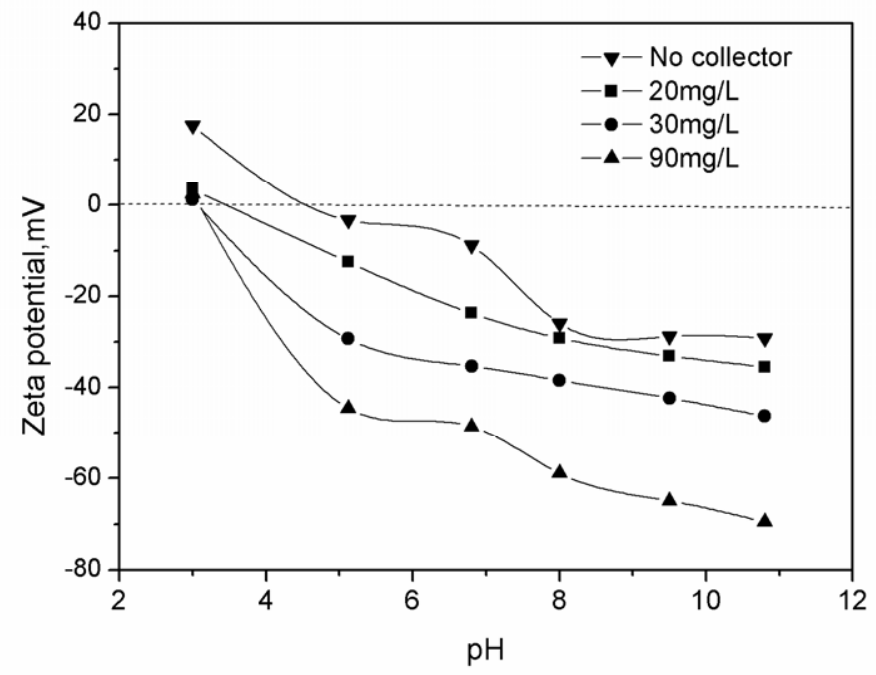

Fig. 9. Effect of the concentration of the mixed collector and the $\mathrm{pH}$ on the zeta potential of the apatite 


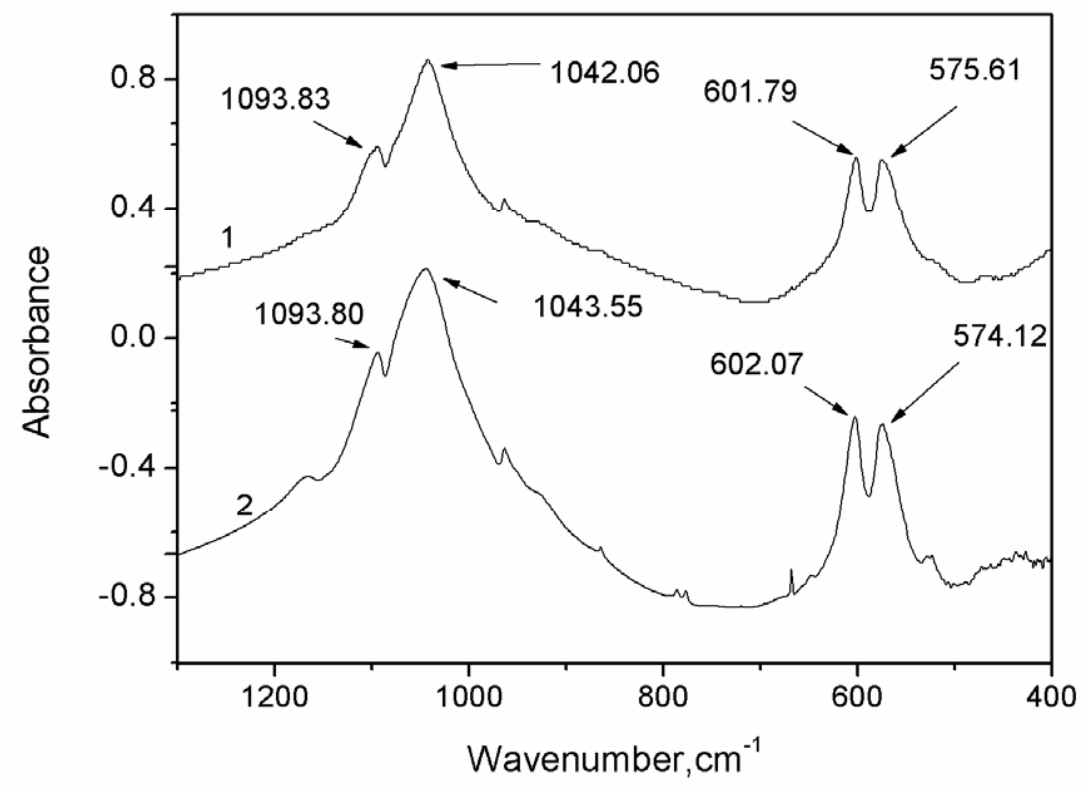

Fig. 10. FTIR spectra of the apatite before (1) and after (2) the mixed collector adsorption in the range from $400 \mathrm{~cm}^{-1}$ to $1300 \mathrm{~cm}^{-1}$ 


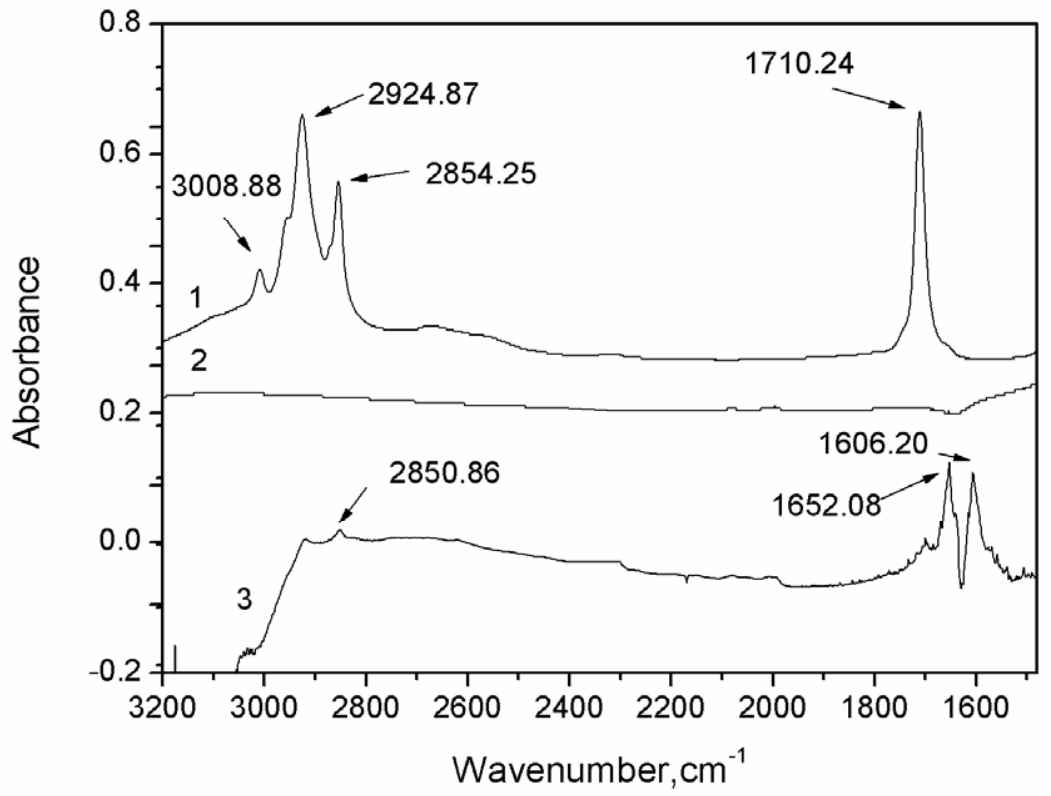

Fig. 11. FTIR spectra of the mixed collector (1), the apatite before (2) and after (3) reaction with the mixed collector in the range from $1480 \mathrm{~cm}^{-1}$ to $3200 \mathrm{~cm}^{-1}$ 


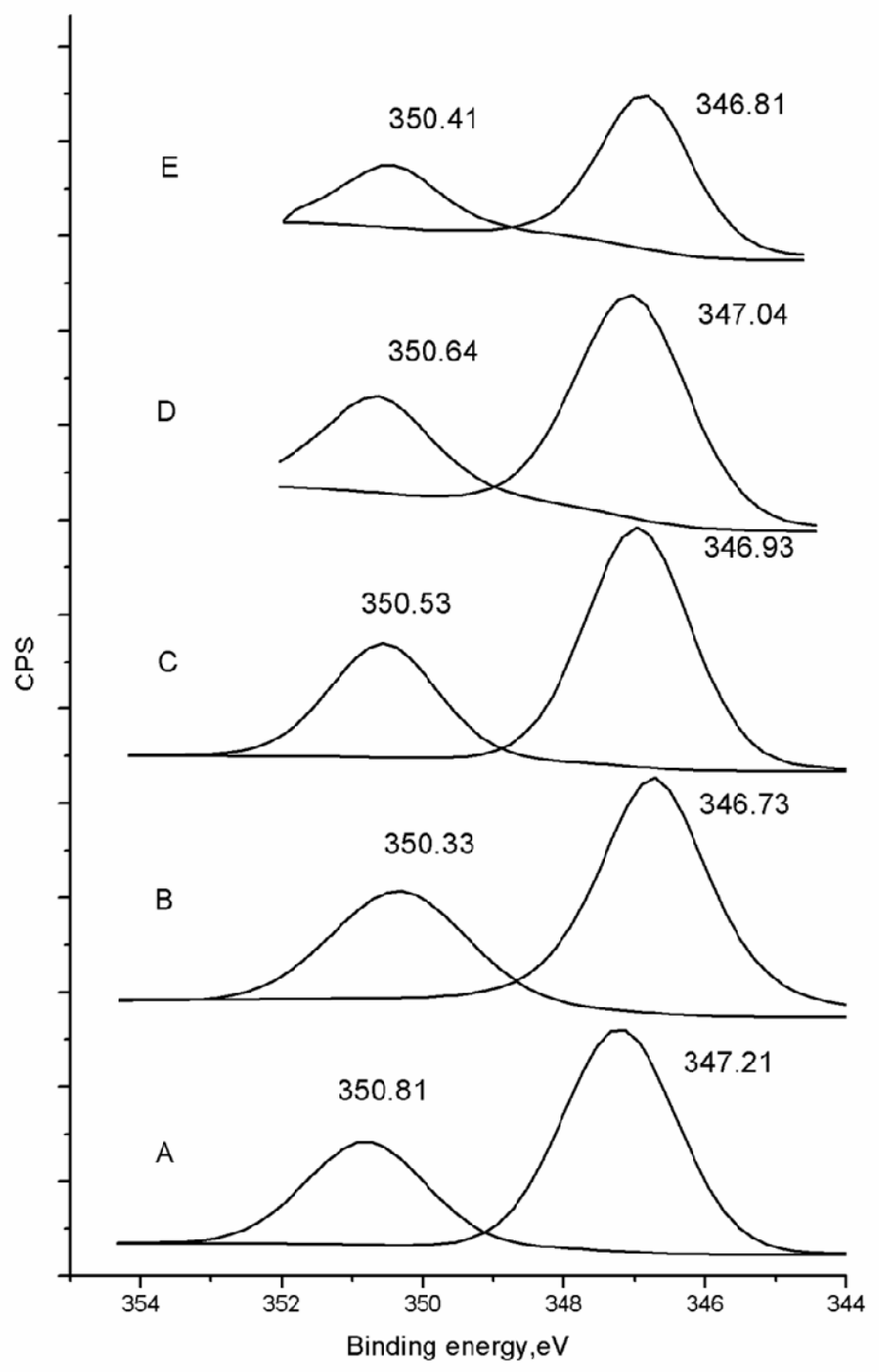

Fig. 12. $\mathrm{Ca}_{2 \mathrm{p}}$ XPS spectra of the natural apatite (A) and the apatite conditioned with $\mathrm{HOl}$ (B), LA (C), LNA (D), the mixed collector (E) 